\title{
3 Research Square

\section{Integrative Analysis of Key Candidate Genes and Signaling Pathways in Acute Coronary Syndrome Related to Obstructive Sleep Apnea by bioinformatics}

\author{
Yanxi Shi \\ Jiaxing Second Hospital \\ Zhengye Jiang \\ Xiamen University \\ Liqin Jiang ( $\nabla$ jlq3038@163.com ) \\ Jiaxing Second Hospital
}

\section{Research Article}

Keywords: Differentially Expressed Genes, Obstructive sleep apnea, Acute coronary syndrome, Unstable Angina, Myocardial infarction, Signaling pathway

Posted Date: January 25th, 2021

DOI: https://doi.org/10.21203/rs.3.rs-151549/v1

License: (c) (1) This work is licensed under a Creative Commons Attribution 4.0 International License.

Read Full License

Version of Record: A version of this preprint was published at Scientific Reports on July 8th, 2021. See the published version at https://doi.org/10.1038/s41598-021-93789-2. 


\section{Abstract}

Background: Although obstructive sleep apnea (OSA) has been clinically reported to be associated with acute coronary syndrome (ACS), the pathogenesis between the two is unclear. Herein, we analyzed and screened out the prospective molecular marker.

Methods: To explore the candidate genes, as well as signaling cascades involved in ACS related to OSA, we extracted the integrated differentially expressed genes (DEGs) from the intersection of genes from the Gene Expression Omnibus (GEO) cohorts and text mining, followed by enrichment of the matching cell signal cascade through DAVID analysis. Moreover, the MCODE of Cytoscape software was employed to uncover the protein-protein interaction (PPI) network and the matching hub gene.

Results: A total of 17 and 43 integrated human DEGs in unstable Angina (UA) and myocardial infarction (MI) group associated with OSAs were uncovered, respectively, that met the criteria of llog2 fold change $(F C) \mid \geq 1$, adjusted $P<0.01$. After PPI network construction, the top five hub genes associated with UA were extracted, including APP, MAPK3, MMP9, CD40 and CD40LG, whereas those associated with MI were PPARG, MAPK1, MMP9, AGT, and TGFB1.

Conclusions: The establishment of the above-mentioned candidate key genes, as well as the enriched signaling cascades provides promising molecular marker for OSA-related ACS, which may help the diagnosis and treatment of ACS patients in the future.

\section{Introduction}

Obstructive sleep apnea (OSA) represents a severely underdiagnosed ( 80\%) form of sleep disordered breathing ${ }^{1-6}$. Ostructive sleep apnea (OSA) is highly prevalent in patients with cardiovascular diseases ${ }^{7,8}$. Increasing evidence indicates that OSA is associated with incidence and progression of coronary artery disease $^{9-11}$ and cerebrovascular disease ${ }^{12}$. Compared with the general population, prevalence of OSA is higher in acute coronary syndrome (ACS) patients and ranges from $36-63 \%$ across various ethnicities ${ }^{13}$. Notably, among patients with coronary artery disease, those with ACS represent a high-risk subset and generally have higher mortality than patients with stable angina ${ }^{14}$. Meanwhile, previous observational studies have examined whether OSA significantly increased risk of recurrent cardiovascular events in patients with ACS and/or undergoing percutaneous coronary intervention $(\mathrm{PCl})^{15-18}$. Despite the huge advancements in ACS research, the prognosis of ACS treatment is still poor. With the onset age of ACS patients getting younger gradually, it is imperative for us to establish the etiology, as well as the molecular features of ACS disease. Therefore, we explore the molecular biomarkers by studying the correlation between OSA and ACS disease to provide evidence for early diagnosis, prevention, as well as the treatment of this disease.

At present, high-throughput sequencing techniques, such as molecular diagnosis, prognosis estimation, as well as drug target discovery, and, which can be employed to assess the gene expression differences, 
as well as the variable splicing variation, are gradually considered to have important clinical significance in disease research. The Integrated Gene Expression Database (GEO), a publicly available websites supported by the National Center for Biotechnology Information (NCBI), harbors dozens of basic experimental disease gene expression patterns and is extensively employed to explore key genes and prospective mechanisms of disease onset and development ${ }^{19}$. Though the pathogenesis of OSA has been found to be related to ACS recently, its pathogenesis, as well as the molecular mechanism remain unknown. Hence, we need to utilize the gene expression chip in the bulletin database and analyze its data through modern software to find new diagnostic markers and therapeutic targets ${ }^{20}$.

In this study, we retrieved GSE60993 and GSE24519 the human unstable angina (UA) and myocardial infarction (MI) gene expression patterns, respectively, from the GEO website. After that, R software (version 3.6.3) installed Limma package was utilized to screen the differentially expressed genes (DEGs) ${ }^{21,22}$. Text mining about "Obstructive sleep apnea" was then carried out by the pubmed2ensembl online tool ${ }^{23}$. After the data obtained from microarray, as well as the text mining were intersected to obtain the common gene, GO enrichment and KEGG pathway assessment were performed on the obtained $\mathrm{DEGs}^{24}$. Finally, the protein-protein interaction (PPI) network was developed using the Search Tool for the Retrieval of Interacting Genes (STRING) and Cytoscape software to screen candidate hub genes, as well as the highly relevant functional modules.

\section{Methods}

\section{Data Abstraction}

We abstracted the gene expression chip data GSE60993 and GSE24519 from the NCBI Gene Expression Comprehensive (GEO) web resource (https://www.ncbi.nlm.nih.gov/geo//) ${ }^{19,25}$. The GSE60993 cohort contains seven euthyroid and nine UA samples, while the GSE24519 dataset includes four normal control and four MI samples.

\section{Identification of DEGs}

The core R package was used to process the downloaded matrix files. After normalization, the differences between $\mathrm{UA}$ or $\mathrm{MI}$ and the control group were determined by truncation criteria $\mid \log 2$ fold change $(\mathrm{FC}) \mid \geq$ 1 , adjusted $P<0.05$ ), and selected the remarkable DEGs for downstream analyses ${ }^{26}$.

\section{Text mining}

We carried out the text mining based on the pubmed2ensembl public tool (http://pubmed2ensembl.Is. manchester.ac.uk/). When manipulated, pubmed2ensembl retrieves all the gene names found in the existing literature relevant to the search topic. We searched for the concept of 
"obstructive sleep apnea". We then screened all the genes associated with the topic from the results. Finally, we used the gene set obtained by text mining and the previously obtained differential gene set for the next step of analysis after the intersection.

\section{Gene Ontology Analysis of DEGs and KEGG pathway analysis}

The obtained DEGs were imported to David V. 6.8 (https://david.ncifcrf.gov/). The GO annotation and KEGG pathway enrichment were carried out in the web resource, which provided a sequence of functional annotation tools for systematic analysis of biological significance of gene lists. The above gene tables were analyzed with $\mathrm{P}<0.05$ as the significant threshold.

\section{Assessment of the PPI network of the DEGs}

We used the STRING online search tool to analyze the protein-protein interaction (PPI) data encoded by $\mathrm{DEG}^{27}$, and only the combination score $>0.6$ was considered significant. Then, the PPI network was analyzed and visualized by using Cytoscape, and the first five hub genes were determined as per the connectivity between des. The standard default setting of the MCODE parameter. The function enrichment of DEGs of each module was analyzed by $\mathrm{P}<0.05$ as the cutoff standard.

\section{Results}

\section{DEGs identification}

Firstly, 587 DEGs were selected from UA samples and normal controls in the GSE60993 data set through limma package screening of R software. Of these, 299 upregulated genes and 288 downregulated genes were selected. At the same time, 2916 differentially expressed genes, including 1647 upregulated genes and 1269 downregulated genes, were obtained by analyzing the MI samples in the GSE24519 data set and the normal control group. Then, the overall distribution of the two data sets and the first 100 DEGs are represented by volcano map and heat map respectively (Fig. 1A-D). Using $\mid \log 2$ fold change (FC) $\mid \geq 1$ criteria and adjusted $\mathrm{P}<0.05$.

Through text mining, 339 human genes associated with OSA. After the DEGs in the microarray data were crossed, the intersection of selected genes was obtained, and 17 genes involved in UA group and 43 genes involved in Ml group were obtained (Fig. 2A-B).

\section{Function and Signal Pathway Enrichment Analysis}


After introducing the DEGs obtained above into DAVID, we subjected them to GO and KEGG enrichment analysis. The purpose of this study is to study the biological functions of DEGs integrated in UA and MI associated with chronic periodontitis. In the $\mathrm{GO}$ analysis results, 27 biological process terms (BP), 15 cell component terms (CC), and 8 molecular function terms (MF) were uncovered in the DEGs integrated by UA. The $\mathrm{P}<0.05$ signified threshold significance. Overall, 6 genes were primarily abundant in BP term to "inflammatory response", 11 genes are located in the "plasma membrane" of CC term, and 15 genes were abundant in the MF term "protein binding" as indicated in Fig. 3. For MI, integrated DEGs were remarkably abundant in $139 \mathrm{GO}$ terms consisting of $103 \mathrm{BP}$ terms, $18 \mathrm{CC}$ terms, as well as $18 \mathrm{MF}$ terms. Besides, the genes were majorly abundant in the following terms: modulation of positive regulation of gene expression in BP, extracellular space in CC, as well as protein binding in MF, which constituted the top 3 GO annotation terms, in which the integrated genes were most remarkably enriched (Fig. 4).

The KEGG enrichment assessment demonstrated that the integrated DEGs were remarkably enriched in the KEGG cascade Toxoplasmosis, Asthma and Primary immunodeficiency in UA group and Proteoglycans in cancer, Cytokine-cytokine receptor interaction and FoxO signaling pathway in the MI group (Fig. 3-4).

\section{Module screening from the PPI network}

Based on the 17 UA group genes and the $43 \mathrm{MI}$ group genes, the Cytoscape publicly available platform and the STRING resource were employed to develop the PPI network, perform module analysis, as well as visualization. Consequently, we developed a PPI network bearing 24 crosstalk based on 15 integrated DEGs related to UA (Fig. 5A). Moreover, we developed a PPI network in the MI group containing 38 integrated DEGs (Fig. 6A). Based on the degree value, the top five hub genes extracted from the UA group consisted of APP (amyloid beta precursor protein), MAPK3 (mitogen-activated protein kinase 3), MMP9 (matrix metallopeptidase 9), CD40 (CD40 molecule) and CD40LG (CD40 ligand). On the contrary, in the MI group, the top five hub genes were PPARG (peroxisome proliferator activated receptor gamma), MAPK1 (mitogen-activated protein kinase 1), MMP9 (matrix metallopeptidase 9), AGT (angiotensinogen), and TGFB1 (transforming growth factor beta 1) (Table. 1). 
Table 1

Top five hub genes identified from the PPI networks

\begin{tabular}{|llll|}
\hline \multicolumn{2}{|l|}{ Alzheimer disease related genes } & Mild cognitive impairment related genes \\
\hline Gene & Node & Gene & Node \\
\hline APP & 16 & PPARG & 38 \\
\hline MAPK3 & 14 & MAPK1 & 32 \\
\hline MMP9 & 14 & MMP9 & 32 \\
\hline CD40 & 10 & AGT & 22 \\
\hline CD40LG & 8 & TGFB1 & 20 \\
\hline
\end{tabular}

We employed the MCODE algorithm to determine highly interconnected subnets, which are frequently protein complexes, as well as components of cascades as per the topological structure. However, it is found that there is no highly clustered mou module in UA by calculation. So, we selected the two most important modules from MI group for further analysis (Fig 6B-C). Additional functional enrichment assessment of the established modules demonstrated that genes in the MI module were majorly abundant in the GO terms of "glucose homeostasis", "caveola", "enzyme binding", as well as KEGG cascade of "FoxO signaling pathway" (Table. 2). 
Table 2

The significant gene ontology terms of the established modules.

\begin{tabular}{|lllll|}
\hline Term & Category & Description & Count & $P$-value \\
\hline G0:0042593 & BP & glucose homeostasis & 4 & $5.78 \mathrm{E}-05$ \\
\hline G0:0001666 & BP & response to hypoxia & 4 & $2.80 \mathrm{E}-04$ \\
\hline G0:0045893 & BP & positive regulation of transcription, DNA-templated & 5 & $5.01 \mathrm{E}-04$ \\
\hline G0:0005901 & CC & caveola & 3 & $9.53 \mathrm{E}-04$ \\
\hline G0:0005829 & CC & cytosol & 8 & 0.004018 \\
\hline G0:0048471 & CC & perinuclear region of cytoplasm & 4 & 0.008723 \\
\hline G0:0019899 & MF & enzyme binding & 5 & $9.24 \mathrm{E}-05$ \\
\hline G0:0008134 & MF & transcription factor binding & 4 & 0.001189 \\
\hline G0:0005515 & MF & protein binding & 4 & 0.016236 \\
\hline hsa04068 & KEGG & FoxO signaling pathway & 5 & 0.001792 \\
\hline hsa05200 & KEGG & Pathways in cancer & 3 & 0.004964 \\
\hline hsa04152 & KEGG & AMPK signaling pathway & 421747 \\
\hline $\begin{array}{l}\text { GO, Gene ontology. BP. Biological processes. CC. Cellular composition. MF. Molecular function. KEGG, } \\
\text { Kyoto Encyclopedia of Genes and Genomes. }\end{array}$ \\
\hline
\end{tabular}

\section{Discussion}

In a multicenter international study, OSA was shown to independently predict adverse cardiovascular events. Therefore, a new potential treatment method for preventing the progression of ACS has emerged, that is, active treatment OSA. However, at present, the pathogenesis and effective treatment of OSA for ACS remain unclear. Hence, it is imperative to explore the molecular mechanism of the ACS after OCS to determine efficient biomarkers and effective approaches for the diagnosis, monitoring, as well as treatment of patients.

Herein, 17 genes in the UA and 43 genes in MI linked to OSA were uncovered for functional analysis using the GO, as well as the KEGG enrichment assessments. Additionally, the PPARG gene comprised one of the hub genes uncovered by the PPI network. PPARG can adjust the balance between glucose and fatty acid oxidation, which plays an important role in the reconstruction of human myocardial infarction after ischemia ${ }^{28-30}$. Moreover, previous evidence has suggested that PPARG may be a risk factor for cardiovascular diseases such as metabolic syndrome, obesity, diabetes and hypertension ${ }^{31-33}$. PPARG is a member of the nuclear hormone receptor superfamily, which can recruit transcriptional coactivators 
necessary to initiate the transcription of target genes and may also play a protective role in the development of $\mathrm{Ml}^{34,35}$. At the same time, Cao et al. also confirmed that THERE was a significant correlation between PPARG and protection of $\mathrm{MI}^{36}$.

The cleaved product of the glycoprotein amyloid precursor protein is $A B$, which aggregates into $A B$ plaques. According to the amyloid cascade hypothesis, it is these plaques that are responsible for $A D$ pathology ${ }^{37}$. Soluble Ab species can bind to and produce toxicity to various neuronal receptors, leading to cellular oxidative stress and epigenetic-mediated transcription disorders ${ }^{38}$. However, recent studies have shown that soluble $A b$ has beneficial physiological effects on certain functions, such as regulating cellular signaling pathways and synaptic function ${ }^{39}$. The main driving force of the pathological progression of $A D$ is the accumulation of $A$ in the brain, which leads to synaptic loss and neuronal cell death ${ }^{40-42}$. In addition, some evidence has found that the continuous accumulation of cerebrovascular $A$ plays A role in cerebral microhemorrhage ${ }^{43,44}$ and vascular cognitive impairment ${ }^{45}$.

CD40 is a costimulatory molecule in the constitutive expression of $\mathrm{B}$ lymphocytes and is expressed in a variety of cells, such as endothelial cells (ECs), monocytes, macrophages and smooth muscle cells $(\mathrm{SMCs})^{46}$. In Antoniades et al. 's study, CD40 was found to be involved in the immune pathogenesis of ACS ${ }^{47}$ due to its bi-cellular activation through the signaling pathways C-Jun, NF-KB and ERK 1/2, resulting in the secretion of inflammatory cytokines, adhesion molecules, and platelet activation ${ }^{46}$. However, soluble forms of CD40 and CD40L were significantly associated with adverse cardiovascular events in patients with $\mathrm{ACS}^{48,49}$, suggesting that they are potential targets for potential therapeutic agents 47 .

MMP9 has been shown in many studies to be significantly associated with cardiovascular disease. Moreover, it was also confirmed in our results that MMP9 was highly expressed in both datasets. MMP9 is a protease of the MMP family that is capable of degrading a broad spectrum of extracellular matrix components and is held responsible for vascular remodeling and breakdown of the fibrous cap of atherosclerotic lesions leading to plaque vulnerability ${ }^{50}$. MMPs are a family of zinc-dependent proteinases capable of degrading various structural components of ECM, thus leading to ECM destruction and plaque rupture ${ }^{51}$.

MAPK1 is mostly concentrated in the cytoplasm, and activated MAPK1 translocates to the nucleus and activates the expression of target genes in tumor tissues ${ }^{52}$. Many previous studies have demonstrated that MAPK1 plays an important role in atherosclerotic lesions or processes ${ }^{53-55}$. Furthermore, MAPK1 were both up-regulated in Coronary heart disease (CAD $)^{56}$. At the same time, MAPK pathway also plays a role in stroke progression ${ }^{57,58}$.

In addition to the genes described above that are known to be associated with coronary heart disease, we also found four potential targeted genes that have not been clearly reported in the literature. 
MAPK3 referred to as the mitogen-activated protein kinase 3 , is a MAP kinase family member and participates in an extensive array of biological processes, including cell proliferation, as well as angiogenesis. MAPK3 may serve as the intrafollicular mediators that trigger the expansion of the cumulus cell-oocyte complex (COC), as well as the maturation of the oocytes ${ }^{59-61}$. The extracellular, as well as intracellular mitogenic stimuli activate the MAPK3 cascade, which has pivotal functions in cellular differentiation, proliferation and survival ${ }^{62}$. The study of colorectal cancer by Schmitz et al. showed that the expression of MAPK3 is related to poor prognosis ${ }^{63}$.

Angiotensin (AGT) is a plasma globulin of the silk fibroin family, is converted to angiotensin I by renin. Angiotensin converting enzyme (ACE) cleaves angiotensin I and converts to angiotensin II. Angiotensin II then causes increased arterial pressure by participating in intravascular fluid volume elevation and vasoconstriction. Finally, angiotensin II functions through angiotensin receptor type 1 (AGTR1) and angiotensin receptor type 2 (AGTR2) ${ }^{64-67}$.

According to previous reports ${ }^{68-73}$, TGF $\beta 1$ is secreted by a variety of cells, such as peripheral blood monocytes, macrophages, platelets, vascular smooth muscle cells (VSMCs), and renal cells. Its regulatory function on the vessel wall is directed at VSMC, endothelial cells and extracellular matrix. Although there is a significant correlation between TGF $\beta 1$ and the pathogenesis of atherosclerosis, the relationship between plasma TGF $\beta 1$ levels and the risk of ACS remains unclear ${ }^{69,74-76}$. This is because the exact mechanism of TGF $\beta 1$ signaling in the vascular system is still not fully understood $70,71,73,77$.

The CD40L gene consists of five exons and four introns. Studies have shown that if CD40L expression is low or not expressed, impaired immunoglobulin class-switching while mice overexpressing CD40L have chronic inflammation ${ }^{78}$. Notably, a dinucleotide microsatellite with cytosine-adenine (CA) repeats in the CD40LG 3-untranslated region (3-UTR) described as highly polymorphisms have been found to be associated with multiple diseases, such as multiple sclerosis (MS), systemic lupus erythematosus (SLE), and rheumatoid arthritis (RA) ${ }^{79-81}$.

\section{Conclusions}

By employing a sequence of bioinformatics tools for gene expression profiling, we established the core function of candidate key genes, including PPARG and AGT, and the enriched signaling cascades constituting the "FoxO signaling pathway" in the molecular modulation network of ACS via integrated bioinformatic analysis. This provided the prospective targets for the future diagnosis, as well as clinical treatment of ACS. However, in vitro, as well as in vivo studies should be conducted to verify our findings.

\section{Declarations}

\section{Competing of interests}

The authors declare that they have no competing interests. 


\section{Ethical approval}

This article does not contain any studies with human participants or animals performed by any of the authors.

\section{Consent to participate}

Not applicable.

\section{Consent for publication}

All authors consent to the publication of this study.

\section{Availability of data and material}

All data is available under reasonable request.

\section{Code availability}

Not applicable.

\section{Authors' contributions}

YS and ZJ conceived and designed this study. YS wrote this manuscript. LJ revised this manuscript. YS made these figures with the help of ZJ.

\section{Acknowledgements}

None

\section{References}

1. Punjabi, N. M. et al. Sleep-disordered breathing and mortality: a prospective cohort study. PLoS Med. 6, e1000132 https://doi.org/10.1371/journal.pmed.1000132 (2009).

2. Gottlieb, D. J. et al. Prospective study of obstructive sleep apnea and incident coronary heart disease and heart failure: the sleep heart health study. Circulation. 122, 352-360 https://doi.org/10.1161/CIRCULATIONAHA.109.901801 (2010). 
3. Punjabi, N. M. The epidemiology of adult obstructive sleep apnea. Proc Am Thorac Soc. 5, 136-143 https://doi.org/10.1513/pats.200709-155MG (2008).

4. Young, T., Evans, L., Finn, L. \& Palta, M. Estimation of the clinically diagnosed proportion of sleep apnea syndrome in middle-aged men and women. Sleep. 20, 705-706 https://doi.org/10.1093/sleep/20.9.705 (1997).

5. Young, T. et al. Sleep disordered breathing and mortality: eighteen-year follow-up of the Wisconsin sleep cohort. Sleep. 31, 1071-1078 (2008).

6. Young, T. et al. New England Journal of Medicine. 328, 1230-1235 https://doi.org/10.1056/nejm199304293281704 (1993).

7. Javaheri, S. et al. Sleep Apnea: Types, Mechanisms, and Clinical Cardiovascular Consequences. J Am Coll Cardiol. 69, 841-858 https://doi.org/10.1016/j.jacc.2016.11.069 (2017).

8. Drager, L. F. et al. Sleep Apnea and Cardiovascular Disease: Lessons From Recent Trials and Need for Team Science. Circulation. 136, 1840-1850 https://doi.org/10.1161/CIRCULATIONAHA.117.029400 (2017).

9. Arzt, M., Hetzenecker, A., Steiner, S. \& Buchner, S. Sleep-Disordered Breathing and Coronary Artery Disease. Can J Cardiol. 31, 909-917 https://doi.org/10.1016/j.cjca.2015.03.032 (2015).

10. Weinreich, G. et al. Association of obstructive sleep apnoea with subclinical coronary atherosclerosis. Atherosclerosis. 231, 191-197 https://doi.org/10.1016/j.atherosclerosis.2013.09.011 (2013).

11. Tan, A. et al. OSA and coronary plaque characteristics. Chest. 145, 322-330 https://doi.org/10.1378/chest.13-1163 (2014).

12. Martinez-Garcia, M. A. et al. Increased incidence of nonfatal cardiovascular events in stroke patients with sleep apnoea: effect of CPAP treatment. Eur Respir J. 39, 906-912 https://doi.org/10.1183/09031936.00011311 (2012).

13. Koo, C. Y. et al. Effects of Ethnicity on the Prevalence of Obstructive Sleep Apnoea in Patients with Acute Coronary Syndrome: A Pooled Analysis of the ISAACC Trial and Sleep and Stent Study. Heart Lung Circ. 26, 486-494 https://doi.org/10.1016/j.hlc.2016.09.010 (2017).

14. Giustino, G. et al. Impact of Clinical Presentation (Stable Angina Pectoris vs Unstable Angina Pectoris or Non-ST-Elevation Myocardial Infarction vs ST-Elevation Myocardial Infarction) on Long-Term Outcomes in Women Undergoing Percutaneous Coronary Intervention With Drug-Eluting Stents. Am J Cardiol. 116, 845-852 https://doi.org/10.1016/j.amjcard.2015.06.010 (2015).

15. Mazaki, T. et al. Impact of Sleep-Disordered Breathing on Long-Term Outcomes in Patients With Acute Coronary Syndrome Who Have Undergone Primary Percutaneous Coronary Intervention. Journal of the American Heart Association. 5, https://doi.org/10.1161/jaha.116.003270 (2016).

16. Yumino, D., Tsurumi, Y., Takagi, A., Suzuki, K. \& Kasanuki, H. Impact of obstructive sleep apnea on clinical and angiographic outcomes following percutaneous coronary intervention in patients with acute coronary syndrome. Am J Cardiol. 99, 26-30 https://doi.org/10.1016/j.amjcard.2006.07.055 (2007). 
17. Meng, S. et al. Impact of obstructive sleep apnoea on clinical characteristics and outcomes in patients with acute coronary syndrome following percutaneous coronary intervention. $J$ Int Med Res. 37, 1343-1353 https://doi.org/10.1177/147323000903700509 (2009).

18. Lee, C. H. et al. Obstructive Sleep Apnea and Cardiovascular Events After Percutaneous Coronary Intervention. Circulation. 133, 2008-2017 https://doi.org/10.1161/CIRCULATIONAHA.115.019392 (2016).

19. Barrett, T. et al. NCBI GEO: archive for functional genomics data sets-update. Nucleic Acids Res. 41, D991-995 https://doi.org/10.1093/nar/gks1193 (2013).

20. Guo, Y., Bao, Y., Ma, M. \& Yang, W. Identification of Key Candidate Genes and Pathways in Colorectal Cancer by Integrated Bioinformatical Analysis. Int J Mol Sci. 18, https://doi.org/10.3390/ijms18040722 (2017).

21. Racine, J. S. \& RStudio: A Platform-Independent IDE for R and Sweave. Journal of Applied Econometrics. 27, 167-172 https://doi.org/10.1002/jae.1278 (2012).

22. Smyth, G. K. et al. in Bioinformatics and Computational Biology Solution Using R and Bioconductor Statistics for Biology and Health (eds R. Gentalman)397-420(2005).

23. Baran, J., Gerner, M., Haeussler, M., Nenadic, G. \& Bergman, C. M. pubmed2ensembl: a resource for mining the biological literature on genes. PLoS One. 6, e24716 https://doi.org/10.1371/journal.pone.0024716 (2011).

24. Huang da, W., Sherman, B. T. \& Lempicki, R. A. Systematic and integrative analysis of large gene lists using DAVID bioinformatics resources. Nat Protoc. 4, 44-57 https://doi.org/10.1038/nprot.2008.211 (2009).

25. Edgar, R., Domrachev, M. \& Lash, A. E. Gene Expression Omnibus: NCBI gene expression and hybridization array data repository. Nucleic Acids Res. 30, 207-210 https://doi.org/10.1093/nar/30.1.207 (2002).

26. Reiner, A., Yekutieli, D. \& Benjamini, Y. Identifying differentially expressed genes using false discovery rate controlling procedures. Bioinformatics. 19, 368-375 https://doi.org/10.1093/bioinformatics/btf877 (2003).

27. Franceschini, A. et al. STRING v9.1: protein-protein interaction networks, with increased coverage and integration. Nucleic Acids Res. 41, D808-815 https://doi.org/10.1093/nar/gks1094 (2013).

28. Liao, H. H., Jia, X. H., Liu, H. J., Yang, Z. \& Tang, Q. Z. The Role of PPARs in Pathological Cardiac Hypertrophy and Heart Failure. Curr Pharm Des. 23, 1677-1686 https://doi.org/10.2174/1381612822666160928150040 (2017).

29. Finck, B. N. The PPAR regulatory system in cardiac physiology and disease. Cardiovasc Res. 73, 269-277 https://doi.org/10.1016/j.cardiores.2006.08.023 (2007).

30. Zhang, Y. F. et al. Crosstalk between MicroRNAs and Peroxisome Proliferator-Activated Receptors and Their Emerging Regulatory Roles in Cardiovascular Pathophysiology. Ppar Research 2018, doi:10.1155/2018/8530371 (2018). 
31. Wang, L. P. et al. Association between PPAR gamma 2 Pro12Ala polymorphism and myocardial infarction and obesity in Han Chinese in Hohhot, China. Genetics and Molecular Research. 11, 29292938 https://doi.org/10.4238/2012.May.18.13 (2012).

32. Ho, J. S. et al. Association of the PPARG Pro12Ala polymorphism with type 2 diabetes and incident coronary heart disease in a Hong Kong Chinese population. Diabetes Res Clin Pract. 97, 483-491 https://doi.org/10.1016/j.diabres.2012.03.012 (2012).

33. Yilmaz-Aydogan, H. et al. Effects of the PPARG P12A and C161T gene variants on serum lipids in coronary heart disease patients with and without Type 2 diabetes. Molecular and Cellular Biochemistry. 358, 355-363 https://doi.org/10.1007/s11010-011-0987-y (2011).

34. Niu, X. et al. Weighted Gene Co-Expression Network Analysis Identifies Critical Genes in the Development of Heart Failure After Acute Myocardial Infarction. Front Genet. 10, 1214 https://doi.org/10.3389/fgene.2019.01214 (2019).

35. Legchenko, E. et al. PPAR gamma agonist pioglitazone reverses pulmonary hypertension and prevents right heart failure via fatty acid oxidation. Sci. Transl. Med. 10, https://doi.org/10.1126/scitranslmed.aao0303 (2018).

36. Cao, R., Dong, Y. \& Kural, K. C. Integrating Literature-Based Knowledge Database and Expression Data to Explore Molecular Pathways Connecting PPARG and Myocardial Infarction. PPAR Res 2020, 1892375, doi:10.1155/2020/1892375 (2020).

37. Karisetty, B. C. et al. Amyloid-beta Peptide Impact on Synaptic Function and Neuroepigenetic Gene Control Reveal New Therapeutic Strategies for Alzheimer's Disease. Front Mol Neurosci. 13, 577622 https://doi.org/10.3389/fnmol.2020.577622 (2020).

38. Chen, G. F. et al. Amyloid beta: structure, biology and structure-based therapeutic development. Acta Pharmacol Sin. 38, 1205-1235 https://doi.org/10.1038/aps.2017.28 (2017).

39. Brothers, H. M., Gosztyla, M. L. \& Robinson, S. R. The Physiological Roles of Amyloid-beta Peptide Hint at New Ways to Treat Alzheimer's Disease. Frontiers in Aging Neuroscience. 10, https://doi.org/10.3389/fnagi.2018.00118 (2018).

40. Tanzi, R. E. The synaptic A beta hypothesis of Alzheimer disease. Nature Neuroscience. 8, 977-979 https://doi.org/10.1038/nn0805-977 (2005).

41. Selkoe, D. J. Alzheimer's disease is a synaptic failure. Science. 298, 789-791 https://doi.org/10.1126/science.1074069 (2002).

42. Hardy, J. \& Selkoe, D. J. Medicine - The amyloid hypothesis of Alzheimer's disease: Progress and problems on the road to therapeutics. Science. 297, 353-356 https://doi.org/10.1126/science.1072994 (2002).

43. Greenberg, S. M. et al. Detection of Isolated Cerebrovascular beta-Amyloid with Pittsburgh Compound B. Annals of Neurology. 64, 587-591 https://doi.org/10.1002/ana.21528 (2008).

44. Dierksen, G. A. et al. Spatial Relation Between Microbleeds and Amyloid Deposits in Amyloid Angiopathy. Annals of Neurology. 68, 545-548 https://doi.org/10.1002/ana.22099 (2010). 
45. Vermeer, S. E. et al. Silent brain infarcts and the risk of dementia and cognitive decline. New England Journal of Medicine. 348, 1215-1222 https://doi.org/10.1056/NEJMoa022066 (2003).

46. Michel, N. A., Zirlik, A. \& Wolf, D. CD40L and Its Receptors in Atherothrombosis-An Update. Front Cardiovasc Med. 4, 40 https://doi.org/10.3389/fcvm.2017.00040 (2017).

47. Antoniades, C., Bakogiannis, C., Tousoulis, D., Antonopoulos, A. S. \& Stefanadis, C. The CD40/CD 40 ligand system: linking inflammation with atherothrombosis. J Am Coll Cardiol. 54, 669-677 https://doi.org/10.1016/j.jacc.2009.03.076 (2009).

48. Varo, N. et al. Soluble CD40L: risk prediction after acute coronary syndromes. Circulation. 108, 10491052 https://doi.org/10.1161/01.CIR.0000088521.04017.13 (2003).

49. Rondina, M. T. et al. Soluble CD40 ligand as a predictor of coronary artery disease and long-term clinical outcomes in stable patients undergoing coronary angiography. Cardiology. 109, 196-201 https://doi.org/10.1159/000106683 (2008).

50. Galis, Z. S. \& Khatri, J. J. Matrix metalloproteinases in vascular remodeling and atherogenesis: the good, the bad, and the ugly. Circ Res. 90, 251-262 (2002).

51. Virmani, R., Burke, A. P., Farb, A. \& Kolodgie, F. D. Pathology of the vulnerable plaque. J Am Coll Cardiol. 47, C13-18 https://doi.org/10.1016/j.jacc.2005.10.065 (2006).

52. Cargnello, M. \& Roux, P. P. Activation and Function of the MAPKs and Their Substrates, the MAPKActivated Protein Kinases. Microbiology and Molecular Biology Reviews. 75, 50-83 https://doi.org/10.1128/mmbr.00031-10 (2011).

53. Bujold, K. et al. CD36-mediated cholesterol efflux is associated with PPAR gamma activation via a MAPK-dependent COX-2 pathway in macrophages. Cardiovascular. Res. 83, 457-464 https://doi.org/10.1093/cvr/cvp118 (2009).

54. Banfi, C. et al. Statins prevent tissue factor induction by protease-activated receptors 1 and 2 in human umbilical vein endothelial cells in vitro. J Thromb Haemost. 9, 1608-1619 https://doi.org/10.1111/j.1538-7836.2011.04366.x (2011).

55. Chen, Y. L. et al. Inhibition of ERK1/2 and Activation of LXR Synergistically Reduce Atherosclerotic Lesions in ApoE-Deficient Mice. Arteriosclerosis Thrombosis and Vascular Biology. 35, 948-959 https://doi.org/10.1161/atvbaha.114.305116 (2015).

56. Zhu, Y., Yang, T. R., Duan, J. L., Mu, N. H. \& Zhang, T. MALAT1/miR-15b-5p/MAPK1 mediates endothelial progenitor cells autophagy and affects coronary atherosclerotic heart disease via mTOR signaling pathway. Aging-Us. 11, 1089-1109 https://doi.org/10.18632/aging.101766 (2019).

57. Sawe, N., Steinberg, G. \& Zhao, H. Dual roles of the MAPK/ERK1/2 cell signaling pathway after stroke. J Neurosci Res. 86, 1659-1669 https://doi.org/10.1002/jnr.21604 (2008).

58. Clancy, P., Koblar, S. A. \& Golledge, J. Angiotensin receptor 1 blockade reduces secretion of inflammation associated cytokines from cultured human carotid atheroma and vascular cells in association with reduced extracellular signal regulated kinase expression and activation. Atherosclerosis. 236, 108-115 https://doi.org/10.1016/j.atherosclerosis.2014.06.011 (2014). 
59. Park, J. Y. et al. EGF-like growth factors as mediators of LH action in the ovulatory follicle. Science. 303, 682-684 https://doi.org/10.1126/science.1092463 (2004).

60. Shimada, M., Hernandez-Gonzalez, I., Gonzalez-Robayna, I. \& Richards, J. S. Paracrine and autocrine regulation of epidermal growth factor-like factors in cumulus oocyte complexes and granulosa cells: key roles for prostaglandin synthase 2 and progesterone receptor. Mol Endocrinol. 20, 1352-1365 https://doi.org/10.1210/me.2005-0504 (2006).

61. Hsieh, M. et al. Luteinizing hormone-dependent activation of the epidermal growth factor network is essential for ovulation. Molecular and Cellular Biology. 27, 1914-1924 https://doi.org/10.1128/mcb.01919-06 (2007).

62. Schubbert, S., Shannon, K. \& Bollag, G. Hyperactive Ras in developmental disorders and cancer. Nat Rev Cancer. 7, 295-308 https://doi.org/10.1038/nrc2109 (2007).

63. Schmitz, K. J. et al. Activation of extracellular regulated kinases (ERK1/2) but not AKT predicts poor prognosis in colorectal carcinoma and is associated with k-ras mutations. Virchows Arch. 450, 151159 https://doi.org/10.1007/s00428-006-0342-y (2007).

64. Brand, E. et al. Detection of putative functional angiotensinogen (AGT) gene variants controlling plasma AGT levels by combined segregation-linkage analysis. European Journal of Human Genetics. 10, 715-723 https://doi.org/10.1038/sj.ejhg.5200874 (2002).

65. George, A. J., Thomas, W. G. \& Hannan, R. D. The renin-angiotensin system and cancer: old dog, new tricks. Nature Reviews Cancer. 10, 745-759 https://doi.org/10.1038/nrc2945 (2010).

66. Yin, G., Yan, C. \& Berk, B. C. Angiotensin II signaling pathways mediated by tyrosine kinases. Int J Biochem Cell Biol. 35, 780-783 https://doi.org/10.1016/s1357-2725(02)00300-x (2003).

67. Sobczuk, P., Szczylik, C., Porta, C. \& Czarnecka, A. M. Renin angiotensin system deregulation as renal cancer risk factor (Review). Oncology Letters. 14, 5059-5068 https://doi.org/10.3892/ol.2017.6826 (2017).

68. Nikol, S. et al. Expression of transforming growth factor-beta 1 is increased in human vascular restenosis lesions. J Clin Invest. 90, 1582-1592 https://doi.org/10.1172/JCl116027 (1992).

69. Frutkin, A. D. et al. TGF-[beta]1 limits plaque growth, stabilizes plaque structure, and prevents aortic dilation in apolipoprotein E-null mice. Arterioscler Thromb Vasc Biol. 29, 1251-1257 https://doi.org/10.1161/ATVBAHA.109.186593 (2009).

70. Schulick, A. H. et al. Overexpression of transforming growth factor beta1 in arterial endothelium causes hyperplasia, apoptosis, and cartilaginous metaplasia. Proc Natl Acad Sci U S A. 95, 69836988 https://doi.org/10.1073/pnas.95.12.6983 (1998).

71. Suthanthiran, M. et al. Transforming growth factor-beta 1 hyperexpression in African-American hypertensives: A novel mediator of hypertension and/or target organ damage. Proc Natl Acad Sci US A. 97, 3479-3484 https://doi.org/10.1073/pnas.050420897 (2000).

72. Majesky, M. W., Lindner, V., Twardzik, D. R., Schwartz, S. M. \& Reidy, M. A. Production of transforming growth factor beta 1 during repair of arterial injury. J Clin Invest. 88, 904-910 https://doi.org/10.1172/JCl115393 (1991). 
73. Khan, R., Agrotis, A. \& Bobik, A. Understanding the role of transforming growth factor-beta 1 in intimal thickening after vascular injury. Cardiovasc Res. 74, 223-234 https://doi.org/10.1016/j.cardiores.2007.02.012 (2007).

74. Najar, R. A., Ghaderian, S. M. H. \& Panah, A. S. T. Association of Transforming Growth Factor-beta 1 Gene Polymorphisms With Genetic Susceptibility to Acute Myocardial Infarction. American Journal of the Medical Sciences. 342, 365-370 https://doi.org/10.1097/MAJ.0b013e318215908a (2011).

75. Chen, Y., Dawes, P. T., Packham, J. C. \& Mattey, D. L. Interaction between smoking and functional polymorphism in the TGFB1 gene is associated with ischaemic heart disease and myocardial infarction in patients with rheumatoid arthritis: a cross-sectional study. Arthritis Research \& Therapy. 14, https://doi.org/10.1186/ar3804 (2012).

76. Grainger, D. J. et al. Nature Medicine. 1, 74-79 https://doi.org/10.1038/nm0195-74 (1995).

77. Pardali, E., Goumans, M. J. \& ten Dijke, P. Signaling by members of the TGF-beta family in vascular morphogenesis and disease. Trends Cell Biol. 20, 556-567 https://doi.org/10.1016/j.tcb.2010.06.006 (2010).

78. Clegg, C. H. et al. Thymus dysfunction and chronic inflammatory disease in gp39 transgenic mice. Int. Immunol. 9, 1111-1122 https://doi.org/10.1093/intimm/9.8.1111 (1997).

79. Dai, Y., Masterman, T., Huang, W. \& Hillert, J. Analysis of a CD40 ligand dinucleotide microsatellite in multiple sclerosis. Eur J Immunogenet. 29, 81-85 https://doi.org/10.1046/j.13652370.2002.00270.x (2002).

80. Martin-Donaire, T. et al. Association of the microsatellite in the 3 ' untranslated region of the CD154 gene with rheumatoid arthritis in females from a Spanish cohort: a case-control study. Arthritis Research \& Therapy. 9, https://doi.org/10.1186/ar2288 (2007).

81. Citores, M. J. et al. The dinucleotide repeat polymorphism in the 3 ' UTR of the CD154 gene has a functional role on protein expression and is associated with systemic lupus erythematosus. Annals of the Rheumatic Diseases. 63, 310-317 https://doi.org/10.1136/ard.2003.006148 (2004).

\section{Figures}


A

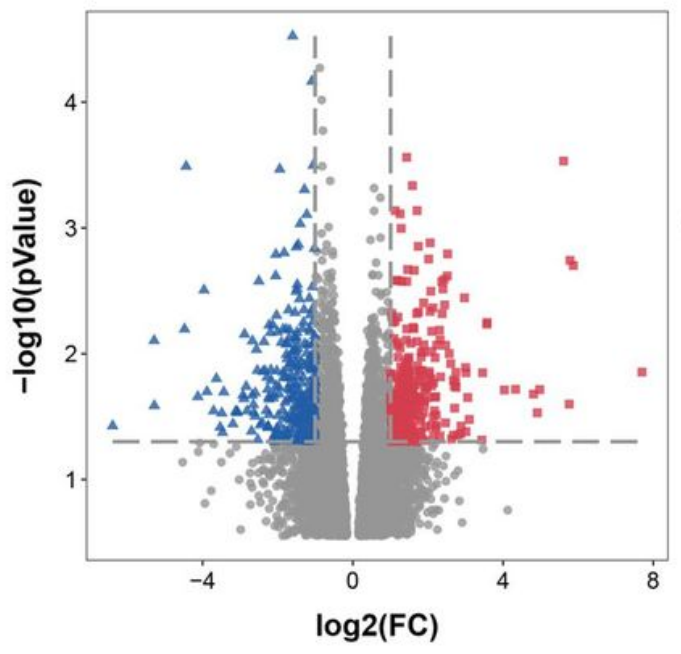

C

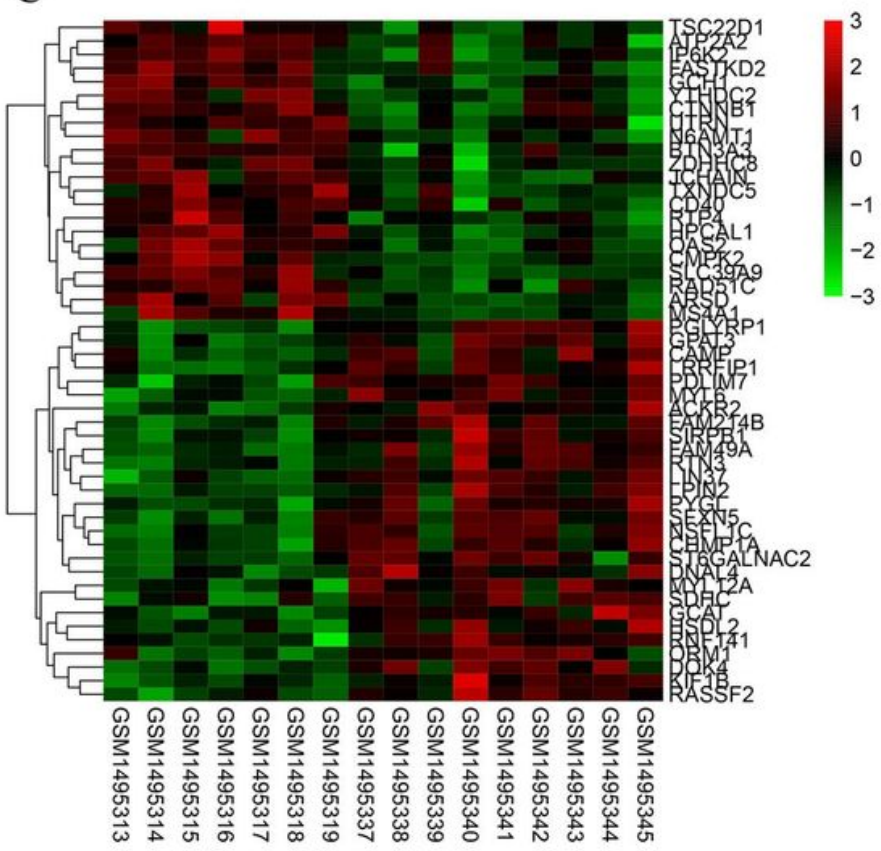

B

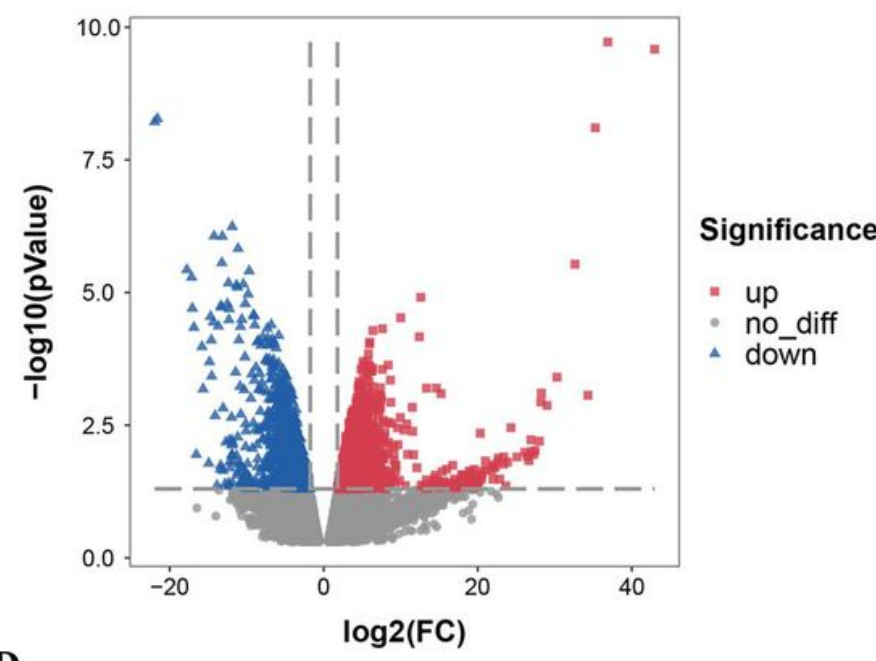

D

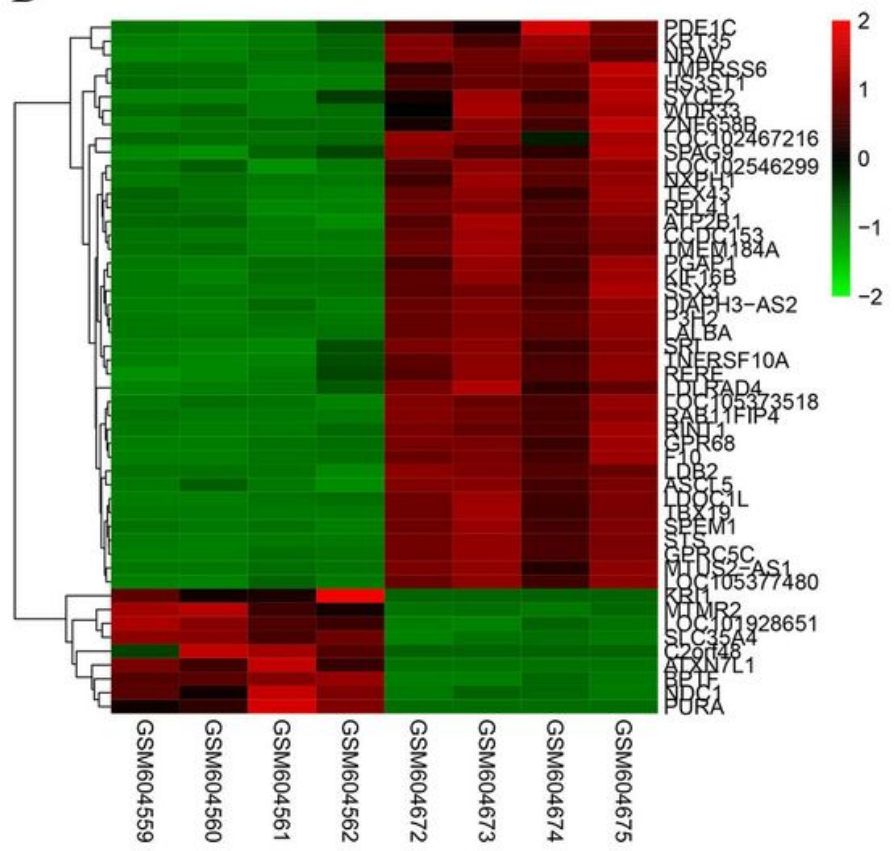

\section{Figure 1}

Differentially expressed genes between unstable Angina/myocardial infarction and control groups. A, C Volcano plot and cluster heat map of the top 50 differentially expressed genes from GSE60993. B, D Volcano plot and cluster heat map of the top 20 differentially expressed genes from GSE24519. Red represents the upregulated genes based on $|\log 2 \mathrm{FC}|>1$ and $\mathrm{P}$ value $<0.05$ and blue represents the downregulated genes based on the same statistical requirements. 
A

Unstable.angina Obstructive.sleep.apnea

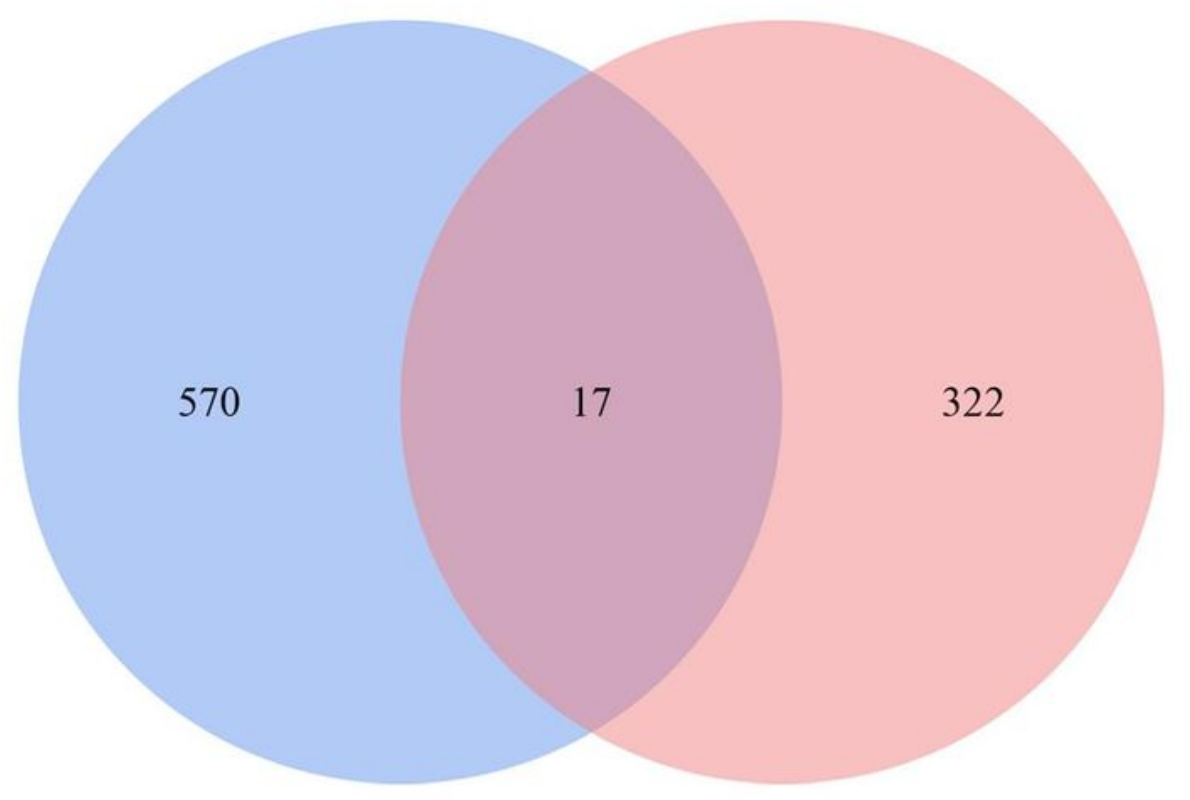

\section{Myocardial.infarction Obstructive.sleep.apnea}

\section{B}

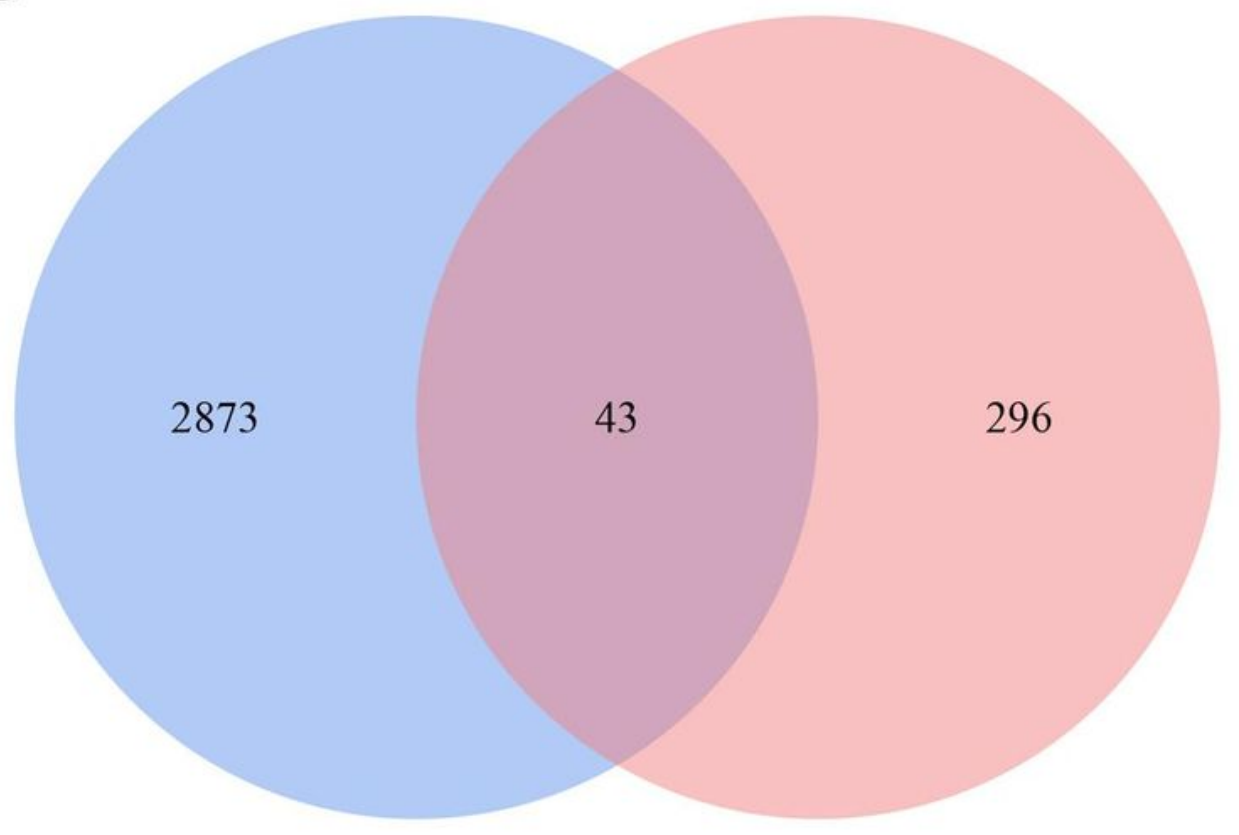

\section{Figure 2}

Venn diagram of DEGs from microarray data and genes list from text mining. A Intersection of genes between DEGs generated from GSE60993 and obstructive sleep apnea gene list from text mining. B Intersection of genes between DEGs generated from GSE24519 and obstructive sleep apnea gene list from text mining. DEGs, differentially expressed genes. 


\section{A Biological Process — Cellular Component \ Molecular Function}

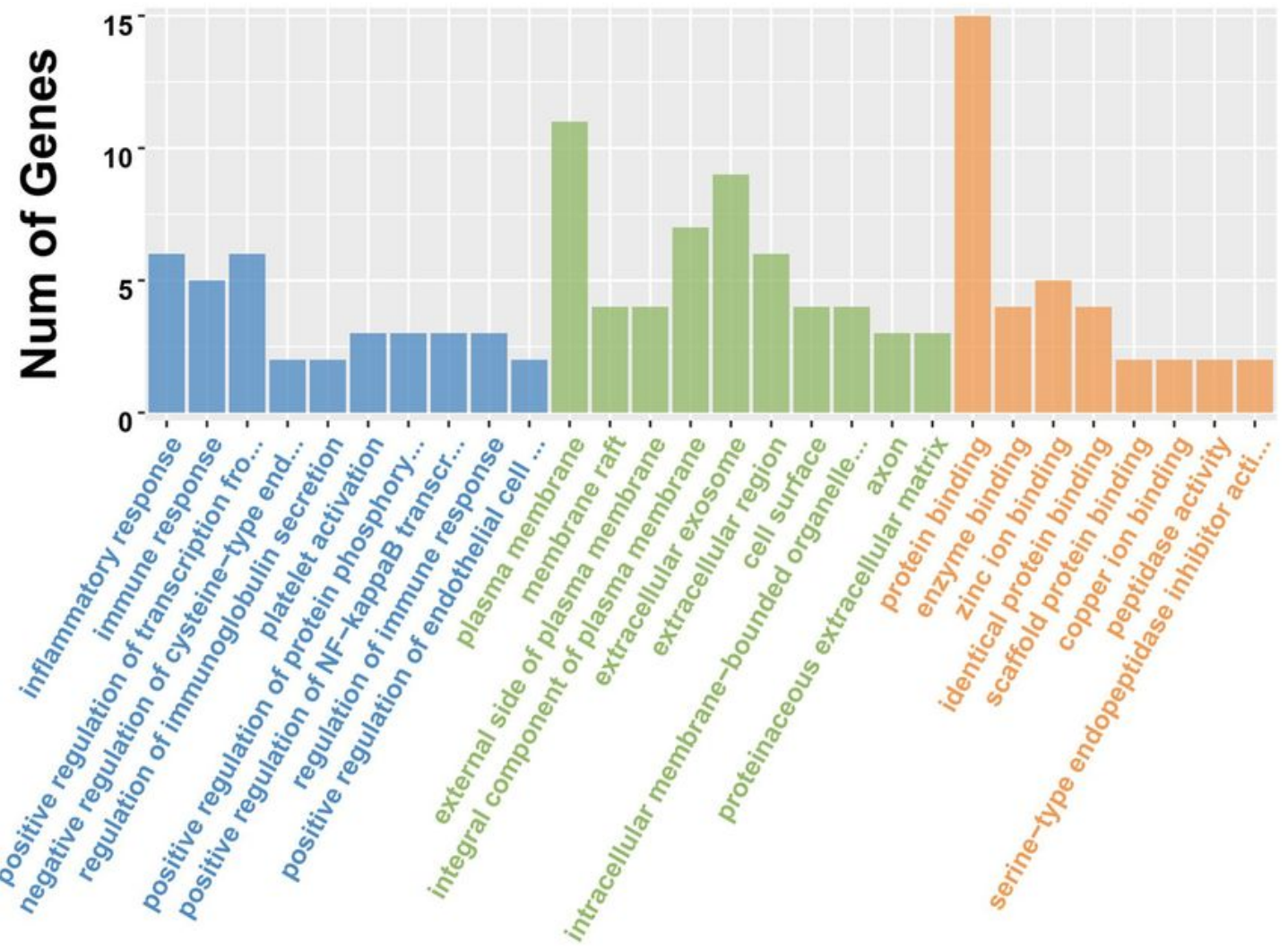

B

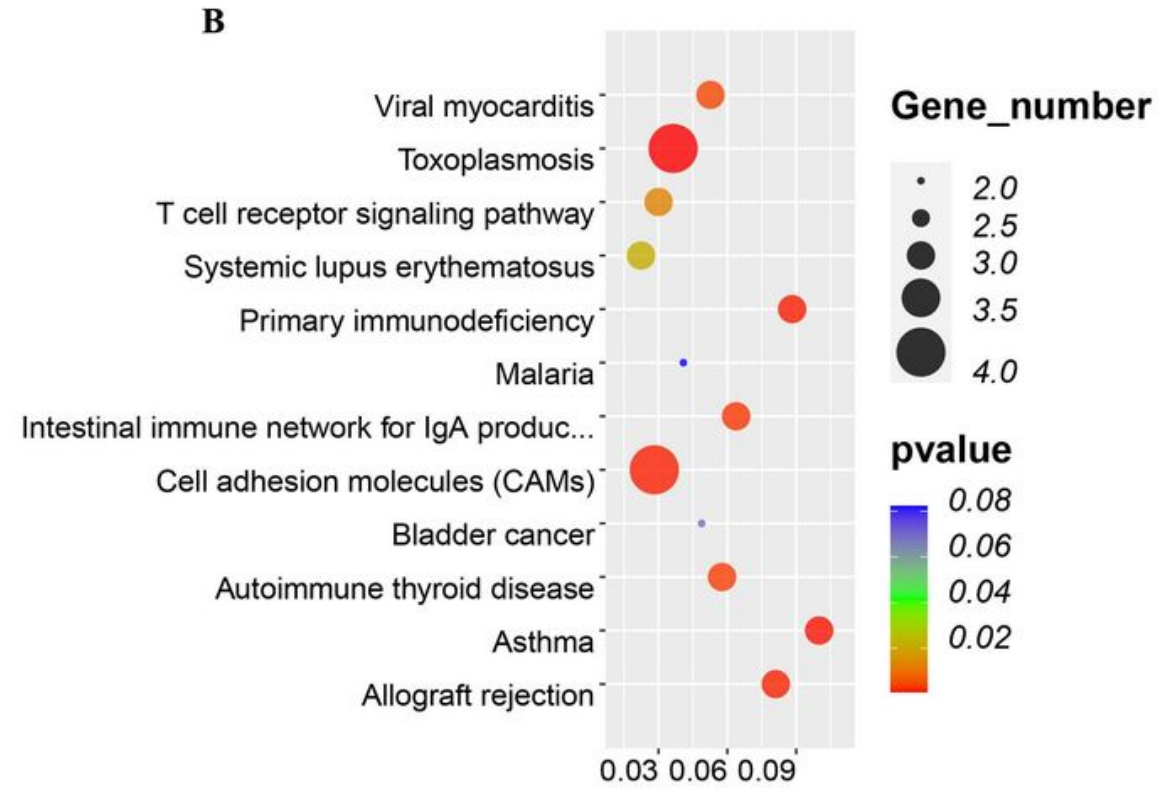

\section{Figure 3}

GO term and KEGG pathway analysis for DEGs significantly associated with unstable Angina and obstructive sleep apnea. A Top $10 \mathrm{GO}$ terms. Number of gene of $\mathrm{GO}$ analysis was acquired from DAVID functional annotation tool. $p<0.05$. (B) KEGG pathway. 
A

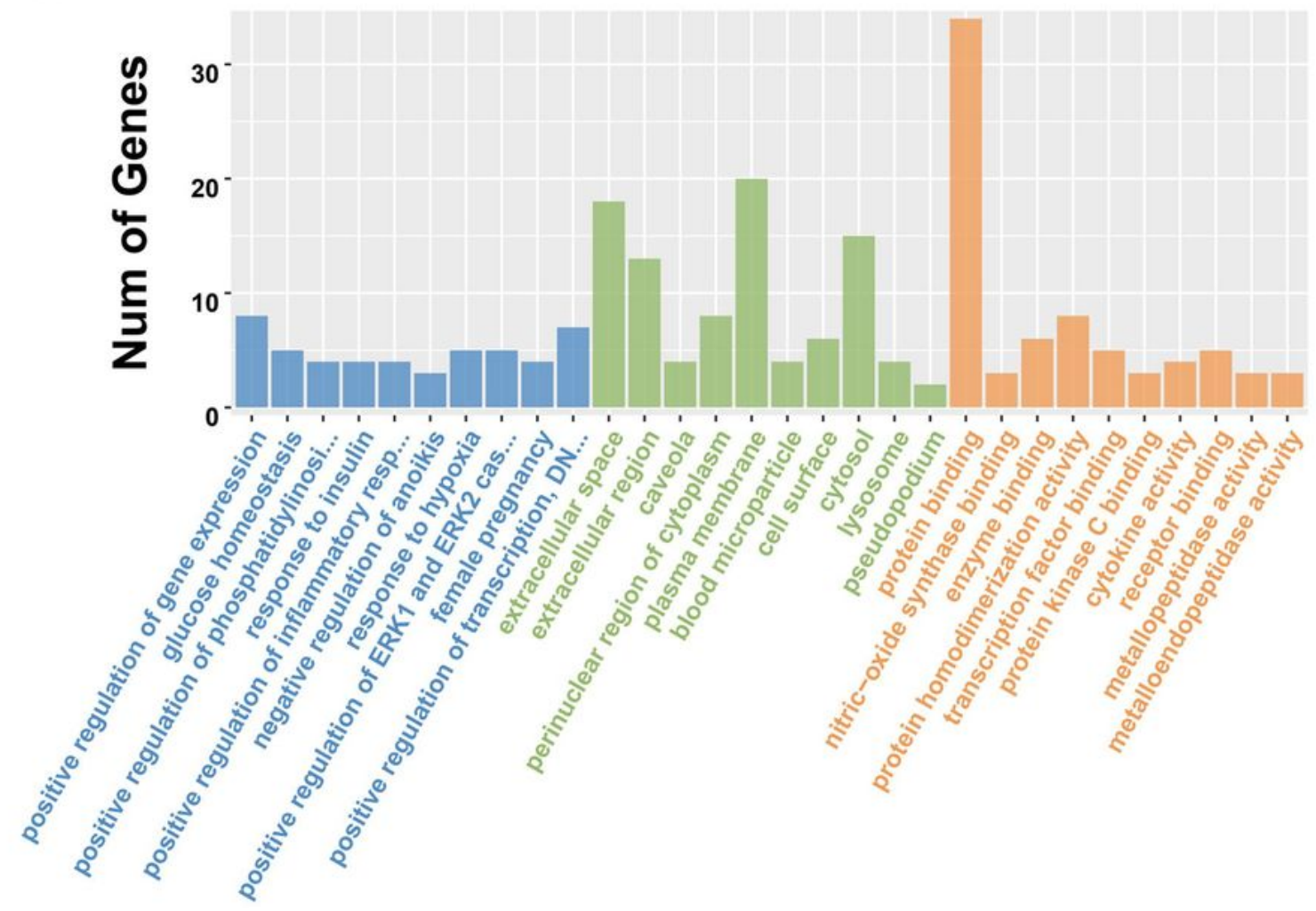

B

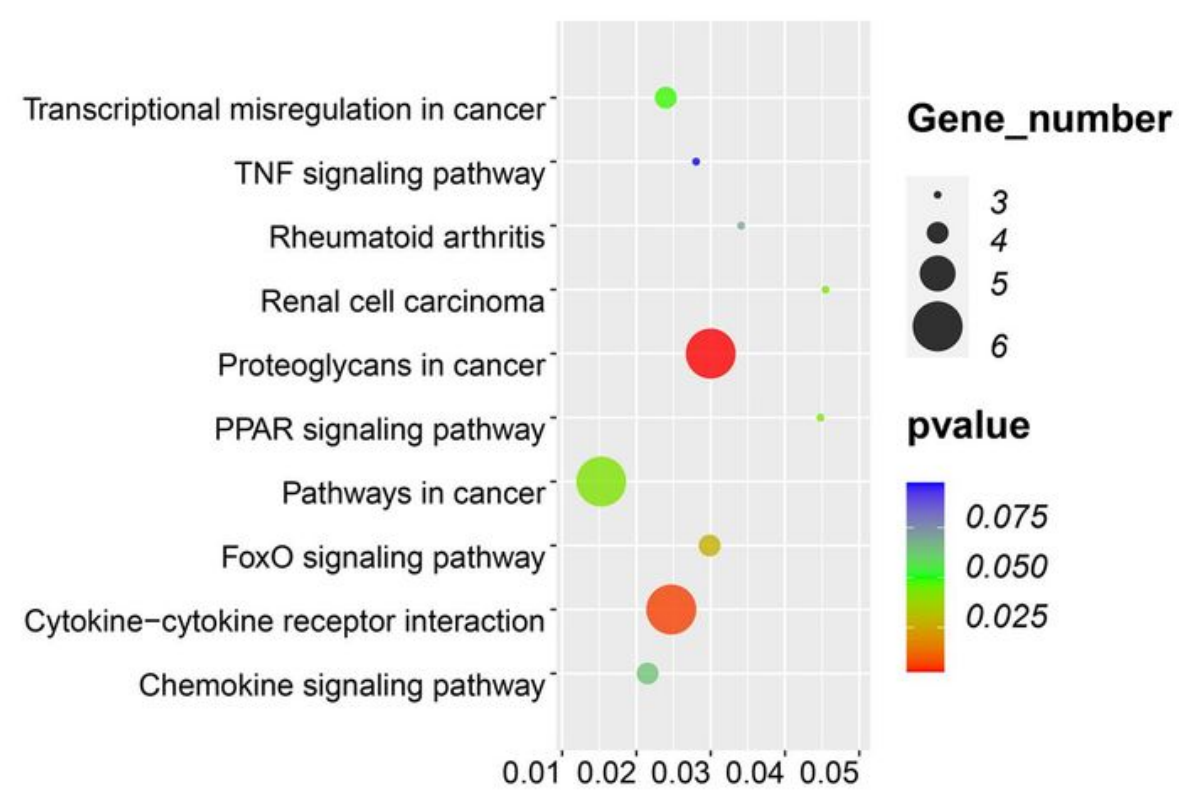

Figure 4

GO term and KEGG pathway analysis for DEGs significantly associated with myocardial infarction and obstructive sleep apnea. A Top $10 \mathrm{GO}$ terms. Number of gene of $\mathrm{GO}$ analysis was acquired from DAVID functional annotation tool. $p<0.05$. (B) KEGG pathway. 


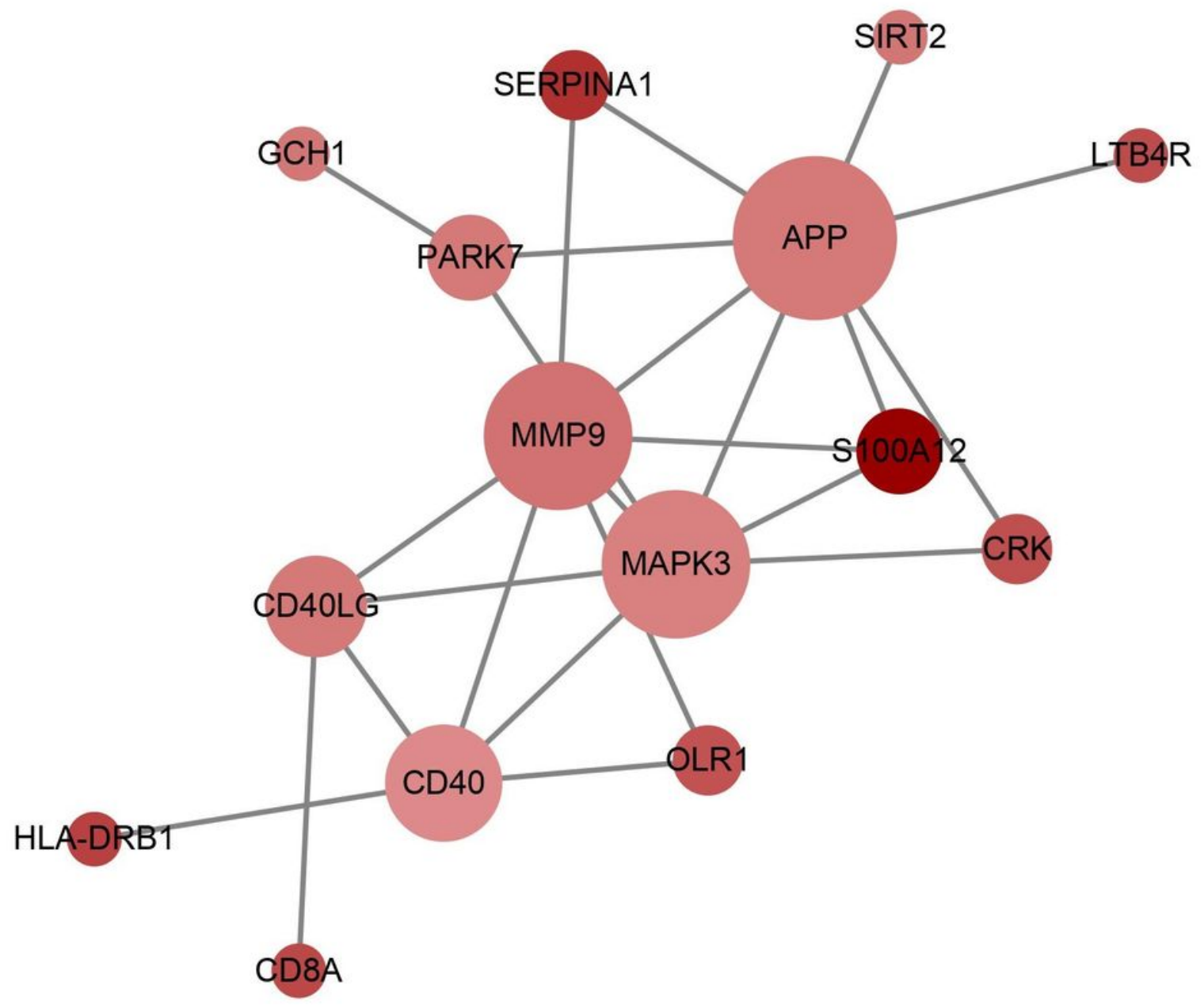

Figure 5

A Based on the STRING online database, 17 genes/node were filtered into the DEG PPI network. The color of a node in the PPI network reflects the $\log (F C)$ value of the $Z$ score of gene expression, and the size of node indicates the number of interacting proteins with the designated protein. 


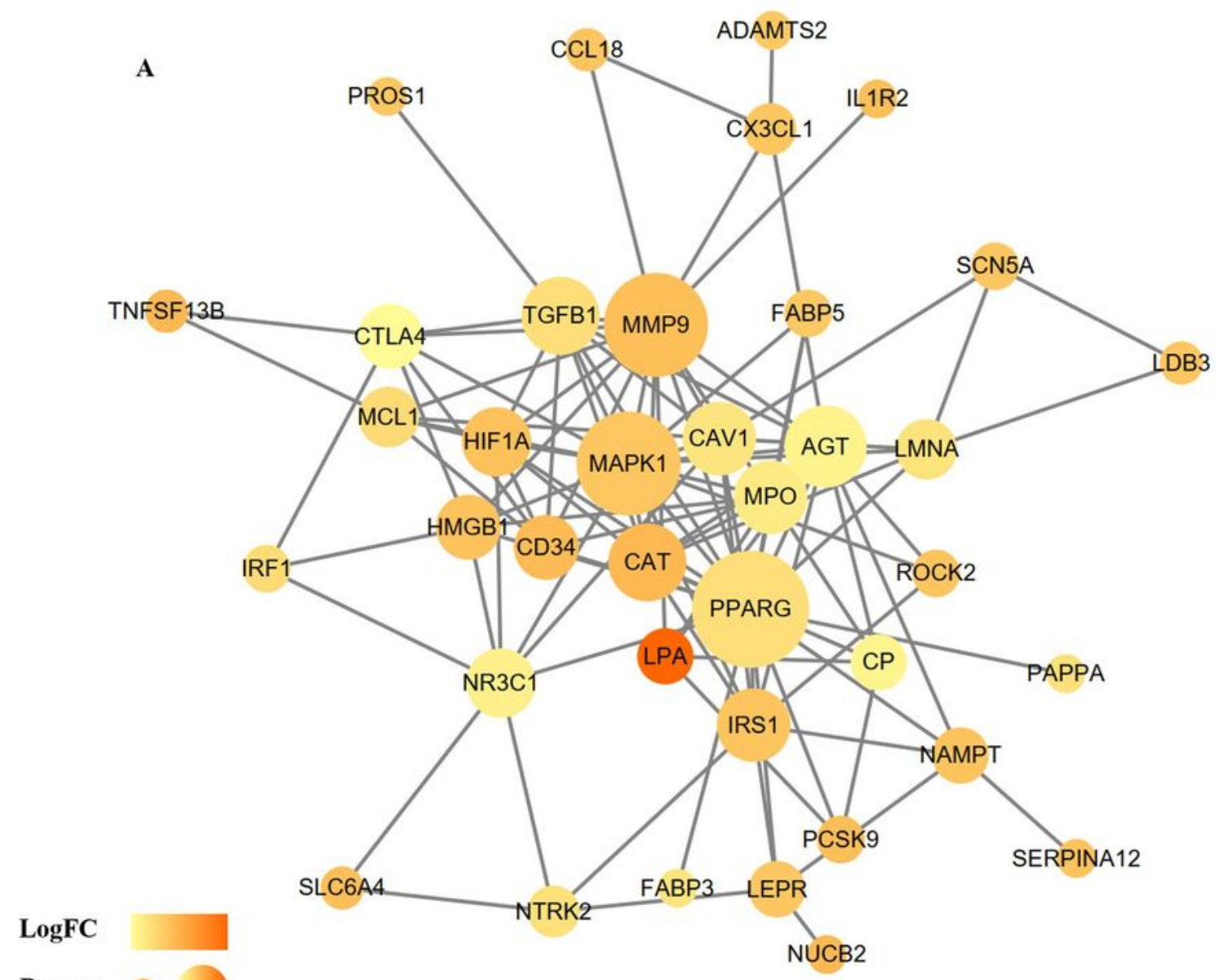

Degre
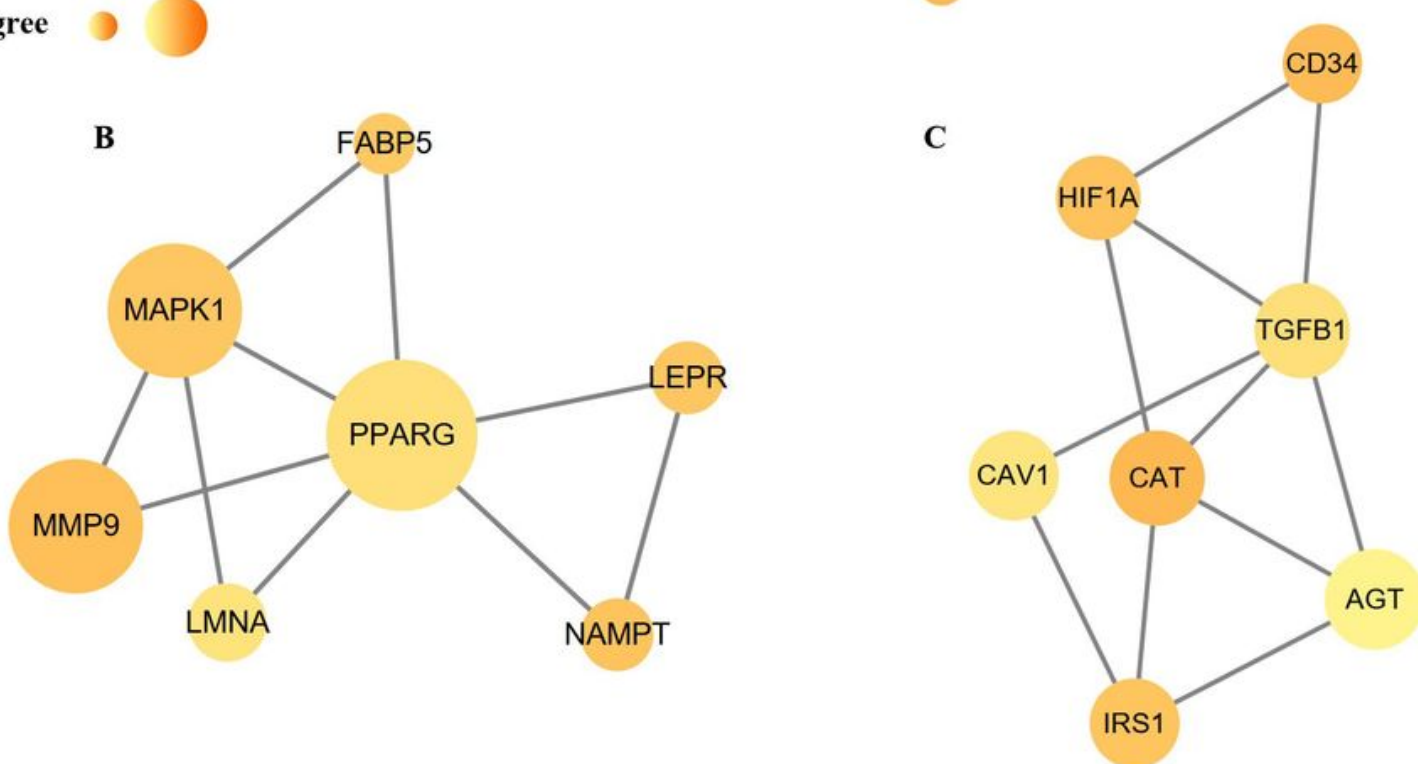

\section{Figure 6}

A Based on the STRING online database, 43 genes/node were filtered into the DEG PPI network. B The most significant module 1 from the PPI network. $C$ The second significant module 2 from the PPI network. The color of a node in the PPI network reflects the log (FC) value of the $Z$ score of gene expression, and the size of node indicates the number of interacting proteins with the designated protein. 